\title{
RED SEMÁNTICA DE TERREMOTO Y MAREMOTO EN PERSONAS EXPUESTAS DIRECTA Y VICARIAMENTE'
}

\author{
Emilio Moyano Díaz \\ Katerinne Muñoz Tapia \\ Claudia Estrada \\ Marcelo Leiva-Bianchi ${ }^{æ}$
}

\begin{abstract}
RESUMEN. Se busca identificar el significado de los conceptos 'terremoto' y 'maremoto' en dos grupos diferentemente expuestos al evento acaecido en Chile el 27/02/2010, en una muestra no probabilística intencional, compuesta por 240 personas provenientes de las ciudades de Constitución ( $\mathrm{n}=104)$ - expuestas directamente al terremoto y maremoto -, y de Punta Arenas ( $\mathrm{n}=136)$ expuestas vicariamente. Mediante redes semánticas naturales (R.S.) construidas ad-hoc, fue observado que terremoto y tsunami tienen significados semejantes, relacionados al miedo, muerte, destrucción, desesperación, desastre, pérdida, angustia, tristeza, pena, dolor y pánico. Adicionalmente, aquellos que vivieron directamente el fenómeno utilizan más definidoras de tipo emocional al definir terremoto que aquellos que fueron expuestos a él de modo vicario.
\end{abstract}

Palabras-clave: Concepto; desastre; miedo.

\section{REDE SEMÂNTICA DE TERREMOTO E TSUNAMI EM PESSOAS EXPOSTAS DIRETAMENTE E VICARIAMENTE}

RESUMO. Procurou-se identificar o significado dos conceitos 'terremoto' e 'tsunami' em dois grupos diferentemente expostos ao evento acontecido no Chile em 27/02/2010, em uma amostra não-probabilística intencional, composta por 240 pessoas provenientes das cidades de Constitución $(n=104)$, expostas diretamente ao terremoto e ao maremoto, e de Punta Arenas $(\mathrm{n}=136)$, expostas vicariamente. Pelas redes semânticas naturais (R.S.) construídas ad hoc, foi observado que terremoto e tsunami têm significados semelhantes, relacionadas a medo, morte, destruição, desespero, desastre, perda, angústia, tristeza, pena, dor e pânico. Além disso, aqueles que experimentaram diretamente o fenômeno tendem a usar mais palavras de cunho emocional para definir terremoto, do que aqueles que foram expostos a ele vicariamen.

Palavras-chave: Conceito; desastre; medo.

\section{SEMANTIC NETWORKS OF EARTHQUAKE AND TSUNAMI IN PEOPLE EXPOSED DIRECTLY AND VICARIOUSLY}

ABSTRACT. The purpose of this research was to describe the meaning of "earthquake" and "tsunami" in two groups with different exposures to the Chilean natural disaster on February 27th, 2010. A non-probabilistic sample of two-hundred-forty

1 Apoio e Financiamento: Programa de Investigación "Calidad de Vida y Ambientes Saludables" (VAC 600 426), Dirección de Investigación, Facultad de Psicología, U. de Talca, Chile.

Psicólogo y licenciado en Psicologia de la Universidad Católica de Chile, docteur en Psychologie de la Université Catholique de Louvain, Bélgica, profesor titular, investigador responsable del Programa de Investigación Calidad de Vida y Ambientes Saludables, Facultad de Psicología, Universidad de Talca, Chile.

\# Psicóloga y licenciada en Psicologia de la Universidad de Talca, Chile, magíster en Psicología Social de la Universidad de Talca, Chile y asistente de la Vice-Rectoría de Docencia de Pregrado, U. de Talca, Chile.

Il Psicóloga y licenciada en Psicología de la Universidad de Chile, magister y doctor en Ciencias Psicológicas de la Universidad Católica de Lovain, Bélgica, profesora Asociada de Escuela de Psicología, Universidad de Magallanes, Chile.

x Psicólogo y licenciado en Psicología de la Universidad de Santiago de Chile, doctor en Psicología de la Universidad Autónoma de Madrid, profesor asistente de la Facultad de Psicología, Universidad de Talca. 
subjects from Constitución ( $n=104)$ and Punta Arenas $(n=136)$ was selected. The first group was directly exposed to the earthquake and tsunami and the second group was indirectly exposed. Natural semantic network analysis (SNA) evidenced that both groups have the same semantic representation of earthquake and tsunami, using emotional words such as fear, death, destruction, despair, disaster, loss, anxiety, sadness, pain and panic. Additionally, those who directly experienced the phenomenon use more emotional words to define earthquake than those exposed to it vicariously.

Key words: Concept; disaster; fear.

Chile tiene una extensa historia de terremotos contando con el más intenso registrado en el mundo hasta hoy, ocurrido en 1960 , en Valdivia, de $9,5^{\circ}$ en la escala Richter. Fue 31 veces más fuerte y liberó 178 veces más energía que el terremoto de Haití en Enero de 2010 y 10 veces más energía que el terremoto de Japón de Marzo 2011 (Ilustre Colegio Oficial de Geólogos, 2011).

Desde 1906 hubo 28 terremotos de más de 6,9 (Richter) (Oficina Nacional de Emergencia [ONEMI], 2010), donde el más reciente ocurrió el 27/02/2010 (27/F/10 en adelante) en el centro-sur del país, a las 03:34:14 hora local, con epicentro en las costas de las regiones del Biobío y del Maule. De intensidad 8, $8^{\circ}$ (Richter) y daños de moderados a severos (United States Geological Survey [USGS], 2010), tuvo como consecuencia un maremoto que avanzó velozmente por el océano Pacífico y al llegar a tierra destruyó casas, puentes, autopistas, y vulneró la estabilidad psicológica de la mayoría de los sobrevivientes, quienes perdieron familiares, bienes y trabajos.

El terremoto del 27/F/10 se extendió por 1.600 kilómetros en Chile percibiéndose desde Puerto Montt por el sur hasta La Serena por el norte (y desde Buenos Aires hasta São Paulo por el oriente). Dada su cercanía al epicentro, una de las ciudades más fuertemente impactadas por el terremoto-maremoto desde el punto de vista de las pérdidas humanas, los daños en la infraestructura y de la salud física y mental de las personas (Panamerican Health Organization [PAHO], 2010) fue Constitución ( $35^{\circ} 20^{\prime}$ latitud sur, $72^{\circ} 30^{\prime}$ longitud oeste), ciudad costera de mayor población (53.000 habitantes) de la región del Maule. Allí, minutos después del terremoto, el mar y el río que la circunda se recogieron, para luego arrasar violentamente con todo, devastando la ciudad (Riquelme, 2010). Después del maremoto las personas que buscaron refugio en los cerros al oriente de la ciudad bajaron a buscar ropa, comida y a ver el estado en que se encontraban sus hogares muchos de los cuales desaparecieron. Se produjo algunos saqueos a supermercados y tiendas, y durante algunos días no hubo comunicación de ningún tipo con el resto del país. La ciudad comenzó a hacerse insalubre con animales y peces muertos, cadáveres depositados en un gimnasio, barro por doquier, sin agua potable para beber, y días soleados que aceleraban procesos de descomposición. Constitución experimentó algo semejante en 1928 con otro sismo de $8^{\circ}$ (Richter) y posterior maremoto que destruyeron esa ciudad (Lorito et al., 2011). La salud mental se ha visto especialmente vulnerada en esta ciudad (PAHO, 2010).

A diferencia de ella, la ciudad de Punta Arenas (región de Magallanes, $53^{\circ} 8^{\prime}$ de latitud sur, 70 53' de longitud oeste, la segunda ciudad más austral del mundo) no fue afectada por el terremoto ni el maremoto del 27/F/10. Sin embargo, por la cobertura que ambos eventos tuvieron en los medios de comunicación, sus habitantes estuvieron vicariamente expuestos al desastre y hay quienes testimonian que existieron problemas de comunicación, personales y de abastecimiento de cierta consideración. Se trata de una zona menos sísmica y cuyo último terremoto ocurrió en XII/1949 con una magnitud de $7.8^{\circ}$ en la escala Richter.

\section{TERREMOTO, MAREMOTO Y VARIABLES PSICOLÓGICAS}

Antes del 27/F/10 la Psicología como ciencia en Chile no se había introducido en la temática de los desastres o riesgos sino excepcionalmente (Moyano Díaz \& Olivos, 1997), de modo que no existe instrumentos psicológicos locales para evaluar el nivel de exposición a desastres ni el impacto psicosocial de los mismos. Aún son muy escasas las investigaciones acerca de los significados que para la población chilena tiene este tipo de eventos y subsisten preguntas acerca de si la exposición diferencial a ellos genera representaciones diferentes. El propósito del presente estudio es, entonces, comparar las redes de significados para dos grupos de habitantes de nuestro país que se diferencian en su nivel de exposición directa versus vicaria- al 27/F/10.

\section{REPRESENTACIÓN SIMBÓLICA DE LOS DESASTRES: RED SEMÁNTICA (R.S.) COMO MÉTODO}

La representación social refiere a cómo las personas aprehenden y significan los sucesos de la 
vida diaria, las características del medio ambiente, las informaciones, el conocimiento de sentido común o el pensamiento natural (Jodelet, 1984, en Moscovici, 1984). Creencias religiosas y otras de tipo y contenido histórico, forman parte de un contexto cultural de base sobre el cual los individuos y grupos forman sus representaciones acerca de los fenómenos naturales. Más allá de las diferencias individuales, existen estereotipos culturales (Tajfel, 1981) para un mismo objeto de significado, que son transversales a toda representación, y sobre los cuales los individuos significan de manera particular su realidad en relación a la experiencia que hayan tenido con el hecho $\mathrm{u}$ objeto determinado (Farr, 1986; Cárdenas, 2008).

La experiencia directa con el fenómeno es un factor central en el significado atribuido a un terremoto o maremoto, así como para el aprendizaje que adquieren las personas acerca de sus causas, manifestaciones, consecuencias y estrategias de afrontamiento. Sin embargo, desde Bandura (1970) sabemos que la mayor parte del aprendizaje humano es de tipo social proveniente de la observación de modelos reales y simbólicos a los cuales imitamos abierta o encubiertamente, no siendo imprescindible la experiencia directa con lo observado para construir o tener una representación de él. Los medios tecnológicos de hoy -internet, telefonía móvil etc.ponen a disposición de millones de observadores objetos y sucesos aconteciendo a enormes distancias. Así, los efectos de la observación de un desastre puede potencialmente afectar a millones de personas deslocalizadas u observando desde lugares remotos al suceso mismo. En Chile y otros lugares, la televisión repitió hasta la saturación imágenes del desastre del 27/F/10, con escenas de dolor y sufrimiento, incluyendo programas especiales con largas $\mathrm{y}$ detalladas entrevistas a quienes sobrevivieron al impacto. Bandura (1986) ha puesto en evidencia que observadores expuestos a experiencias dolorosas experimentan reacciones emocionales lo que contribuye al aprendizaje de las situaciones que están observando, sin pasar por la experiencia directa o en vivo. La reiteración mediática provoca evocación de aquellas imágenes y emociones negativas en quienes han estado expuestos directamente al desastre y eventualmente las genera en quienes han estado expuestos indirectamente. La excitación vicaria, además de su funcionalidad inmediata, puede considerarse como un aspecto integral de la empatía humana, y Bandura (1986) señala que la inducción indirecta de los temores por los medios de comunicación tiene consecuencias sociales más profundas que la experiencia directa, especialmente por la enorme cobertura de la televisión. Es probable que a causa de esta iteración mediática haya habido aprendizaje de respuestas de miedo y angustia en la población chilena en general, y no sólo en quienes estuvieron expuestos directamente al desastre. Las iteraciones posteriores pueden evocar respuestas previamente aprendidas de miedo, temor o angustia.

Un modo de capturar efectos eventuales de la exposición vicaria al desastre es mediante la técnica R.S. que permite recoger una representación del conocimiento que las personas han desarrollado respecto de él. Diversas investigaciones han mostrado la eficiencia de éste método, además de posibilitar la extrapolación del producto resultante a diversas áreas de estudio. Valdez (1998) ha mostrado diversos usos de la técnica, validando su aplicación como instrumento de evaluación del significado psicológico de distintos objetos para analizar los mecanismos involucrados en la asimilación y construcción de significados sociales, y como base en la construcción de instrumentos de medición, procesos de representación, aplicación en la educación y en la evaluación de currículos. En Chile ha sido identificado el significado de los conceptos de participación y de conflicto ambiental (Moyano-Díaz, Maturana \& Villablanca, 2002). Trejo, Camacho, Herrera y González (2011), estudiaron el significado semántico de lactancia materna y lactancia artificial. Zermeño, Arellano y Ramírez (2005) han capturado los significados que jóvenes tienen de la televisión, internet y las expectativas de vida, entre otros.

Otras investigaciones reportan una enumeración de factores y procesos psicológicos involucrados en cómo las personas estructuran imágenes y percepciones del desastre (Moyano Díaz \& Olivos, 1997) o cómo se representa un desastre no natural utilizando los medios de comunicación (Ligi, 2005). Otras tienen su foco en las consecuencias sociales de eventos destructivos de la naturaleza (Enrique, 2002) o en las consecuencias psicológicas y psicopatológicas de los desastres (Jiménez \& Cubillos, 2010; García \& Mardones, 2010).

En el presente estudio se examina mediante la técnica de R. S. (Valdés, 1998) las representaciones acerca de terremoto y maremoto aparentemente no identificadas previamente en Chile ni en Latinoamérica. En nuestro conocimiento no se ha realizado estudios sistemáticos que muestren cómo las personas significan estos fenómenos y si existen diferencias en la percepción del mismo en relación al tipo de exposición. Lo más cercano a esto es el trabajo de Gascón (2009) sobre representaciones verbales y visuales de los desastres incluyendo representaciones lingüísticas, artísticas y periodísticas.

En síntesis, no está del todo claro cómo es la estructura de significados que un grupo de personas que vivió directamente un desastre natural -como el 
del 27F- tiene acerca de dicha experiencia. Tampoco se sabe fundadamente si esta estructura es o no similar a la encontrada en personas que sólo vivieron vicariamente el evento. Esto, probablemente porque no es fácil encontrar grupos de personas pertenecientes a una misma cultura que viviendo en ciudades con emplazamientos geográficos semejantes, hayan tenido la experiencia del evento con tan distintos tipos de exposición. Con esta finalidad, y dado el contexto recientemente vivido por la población chilena, fue realizado el presente estudio.

\section{MÉTODO}

\section{Participantes}

240 personas de ambos sexos (59,2\% mujeres) que vivieron el terremoto y el maremoto del 27/F/10 directa o vicariamente, respectivamente en las ciudades de Constitución ( $n=104)$ y Punta Arenas $(n=136)$, con edades entre 18 y 74 años. En Constitución se buscó a habitantes que perdiendo sus casas por el evento fueron relocalizados en "aldeas", es decir, agrupaciones de viviendas de emergencia denominadas "mediaguas", que son habitáculos de madera sin forro interior, de 18 metros cuadrados, con techo de zinc. Se entrevistó a personas que vivían en alguna de 3 aldeas de emergencia, cuyo nivel de vida es el propio de grupos socioeconómicos bajos o muy bajos. La muestra de Punta Arenas es muy distinta en términos de tipo de habitación y segmento socioeconómico, sin embargo, ambos grupos son alfabetizados y tienen al menos tres rasgos en común: pertenecen a ciudades costeras chilenas susceptibles de sufrir terremotos y maremotos; poseen una misma identidad cultural nacional, es decir, chilena; y estuvieron expuestos a reiteradas imágenes y noticias del 27/F/10.

\section{Recolección de dados y procedimientos}

En Constitución y Punta Arenas estudiantes de psicología entrenados ad-hoc encuestaron la población entre los meses de agosto y septiembre del 2010. En ambas ciudades se aplicó instrumentos mediante el método 'puerta a puerta' previa aceptación del consentimiento informado.

La R.S. aplicada consistió en mostrar en una hoja -y como primer reactivo- la palabra escrita "terremoto" (y al finalizar éste se seguía con 'maremoto') al respondiente, solicitándole escribir las primeras cinco palabras (sustantivos, adjetivos, pronombres o verbos) y un máximo de diez, que vinieran inmediata o espontáneamente a su mente. Posteriormente debía jerarquizarlas de acuerdo al nivel de asociación estimado respecto de la palabra estímulo, asignando el número 1 a la que considerara que mejor definía el concepto-estímulo, 2 a la segunda y así sucesivamente hasta la décima. Se considera como representación y significado de terremoto y de maremoto al conjunto de palabras definidoras que los participantes asociaron respectivamente a ambas palabras estímulos. El procedimiento de análisis de la red semántica tiene 5 pasos que van desde: determinar frecuencia y jerarquía otorgando 10 puntos a la palabra definidora que encabeza la jerarquía (concepto asociado a la palabra estímulo), 9 a la que le sigue y así sucesivamente hasta el final. Luego es calculado el "puntaje J" o total de palabras definidoras distintas (riqueza semántica) generadas por cada grupo de comparación para definir los conceptos estímulos. Entre estas etapas se requiere generar grupos semánticos o agrupación de palabras de una misma familia de significados (Valdez, 1998).

\section{RESULTADOS Y DISCUSIÓN}

Significado de terremoto y maremoto. A partir de las palabras definidoras obtenidas en las R.S. fueron creadas categorías que permiten agrupar las palabras definidoras según su contenido o significado. Para la palabra estímulo terremoto se creó las categorías semánticas: (i) sentimiento o emoción, (ii) consecuencias negativas del desastre, (iii) características propias del terremoto, (iv) hogar, familia y mascotas, (v) sensación o necesidad, (vi) patriotismo, (vii) religión y (viii) acción en el momento del desastre. Para la palabra estímulo maremoto se creó las categorías semánticas (i) sentimiento o emoción, (ii) consecuencias negativas del maremoto, (iii) consecuencias positivas del maremoto, (iv) agua, (v) acción en el momento del maremoto, (vi) hogar familia y mascotas, (vii) alarma, sensación o necesidad, (viii) personas, (ix) características propias del maremoto y $(\mathrm{x})$ religión.

La frecuencia de presentación de palabras definidoras en los núcleos de red muestra que las categorías semánticas "sentimiento o emoción" y "consecuencias del desastre" se presentan transversalmente en todos los núcleos de red para la palabra estímulo terremoto. Para maremoto, además de las dos categorías anteriores, la categoría 'agua' se repite en todos los núcleos de red. En general, sin embargo, los participantes de ambas muestras utilizan mayoritariamente palabras definidoras asociadas a sentimientos o emociones. Las palabras definidoras obtenidas para significar terremoto y maremoto para la totalidad de la muestra son categorizables como "sentimiento o emoción" (53\% y $53 \%$ 
respectivamente), "consecuencias del desastre" (40\% y $27 \%$ respectivamente) y, en menor medida, como "características propias del desastre" (7\% solo para terremoto y 20\% "agua" solo para maremoto). Se observa una diferencia descriptiva importante entre ambas muestras manifestadas en que la directamente expuesta utiliza un $80 \%$ de palabras definidoras asociadas a "sentimientos o emociones" en tanto la muestra vicariamente expuesta utiliza solo un $53 \%$. Para definir maremoto no se observan diferencias entre participantes de ambas muestras en lo que respecta a la cantidad de palabras definidoras asociadas a la categoría semántica "sentimiento o emoción".

Tabela 1. Comparación de categorías semánticas para palabras-estímulo terremoto (A) y maremoto (B) para la muestra completa y subgrupos de comparación según tipo de exposición.

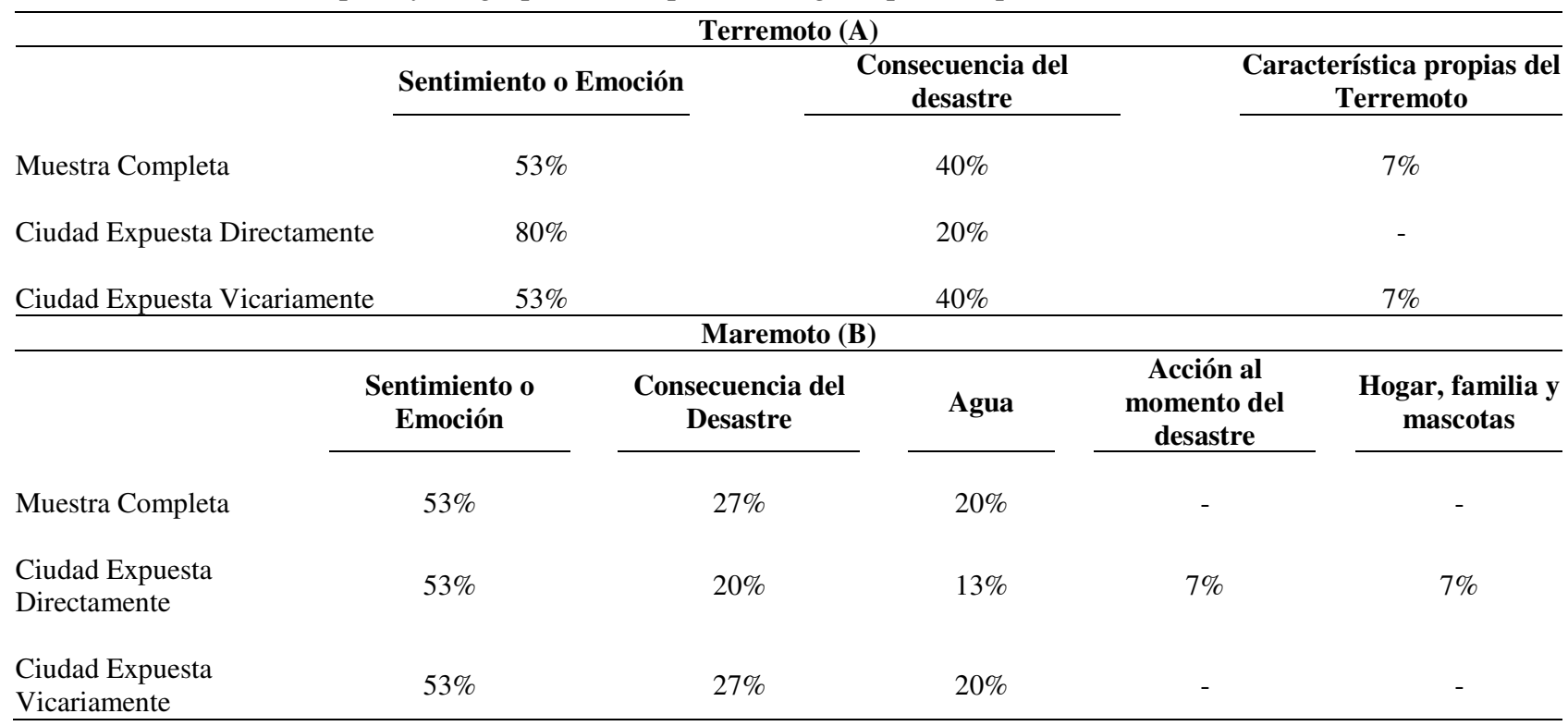

Significado de terremoto para el total de la muestra. Los participantes definen terremoto mediante definidoras relativas a sentimientos $y$ emociones negativas que se generan en el momento del desastre con palabras tales como: miedo, desesperación, angustia, pánico, tristeza, dolor, pena y sufrimiento, también con definidoras referidas a consecuencias del desastre tales como: muerte, desastre, pérdida, destrucción, caos y catástrofe y con una definidora vinculada a características propias del evento mismo: movimiento (Figura 1 A y B). La distancia semántica es operacionalizada como la diferencia porcentual entre una palabra definidora y la palabra definidora de mayor peso (valor M, o cabeza del núcleo de red). Así la palabra "miedo" es la primera de la lista -la más citada o con mayor peso semántico- y por eso se ubica en el centro del gráfico seguida por "muerte" $(42 \%) \mathrm{y}$, en tercer lugar, por "desastre" (55\%).

Significado de maremoto para la muestra total. Aquí se encuentran palabras definidoras relativas a sentimientos y emociones negativas que se generan en el momento del desastre: miedo, desesperación, angustia, pena, terror, tristeza, dolor y pánico, algunas definidoras referidas a consecuencias del desastre: muerte, destrucción, pérdida y desastre, finalmente, palabras referidas a agua: ola, agua y mar. Nuevamente el miedo es la palabra que encabeza la lista del núcleo de red, seguida por muerte y destrucción.

Comparación de significados de terremoto para expuestos directa y vicariamente. El grupo de participantes expuestos de manera directa al desastre muestra un significado de terremoto relacionado principal y mayoritariamente con definidoras categorizables como sentimientos y emociones que se generan en el momento del desastre (miedo, angustia, desesperación, susto, pánico, terror, tristeza, pena, dolor, sufrimiento, temor y preocupación), y con algunas definidoras referidas a consecuencias del desastre -pérdida, muerte y desastre-. Del mismo modo, los participantes expuestos vicariamente utilizan palabras categorizables como sentimientos y emociones negativas que se generan en el momento del desastre: miedo, dolor, tristeza, pánico, pena, desesperación, angustia y sufrimiento. Y también algunas palabras relativas a consecuencias del desastre: muerte, desastre, destrucción, caos, catástrofe y pérdida y una palabra que tal vez sea lo esencial del terremoto como fenómeno físico: movimiento. De las palabras definidoras observadas en el conjunto SAM para la palabra-estímulo 
terremoto para la muestra directamente expuesta, el miedo encabeza la lista, seguido de 'pérdida'. Entre ellas se observa una distancia semántica (FMG) de $60 \%$, es decir, que el peso semántico o importancia de la palabra definidora 'pérdida' para definir terremoto, sigue al de la palabra miedo. Son estas mismas palabras las utilizadas por los participantes expuestos vicariamente al terremoto aunque, a diferencia de los directamente expuestos, entre ambas palabras se observa una distancia semántica de sólo $1 \%$, es decir, ambas definidoras tienen prácticamente un mismo peso semántico (Figura $1 \mathrm{C}$ y D).

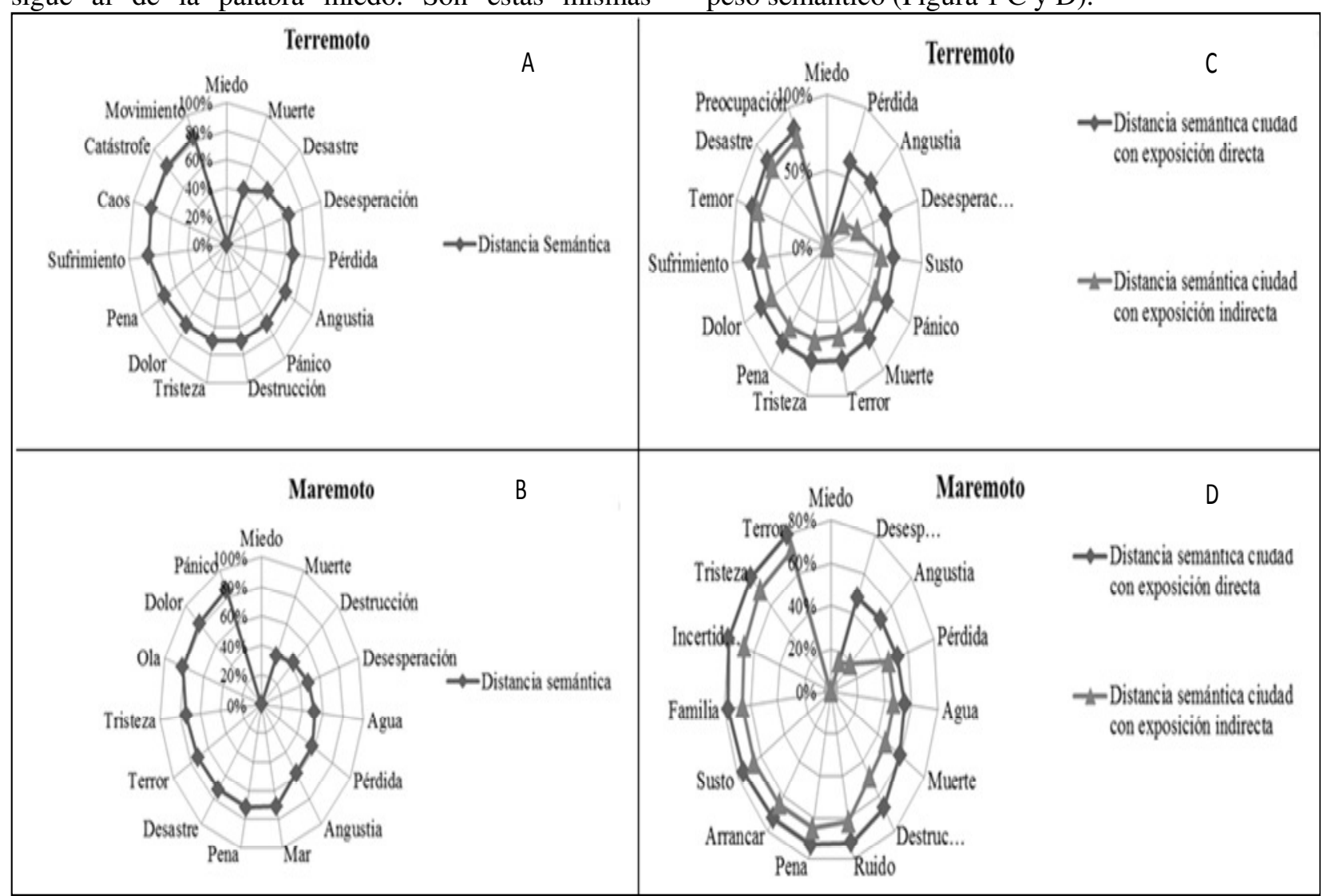

Nota: Las figuras A y B corresponden a la muestra total del estudio para cada uno de los conceptos principales (terremoto y maremoto). Las figuras C y D corresponden a la comparación entre grupo expuesto directa y vicariamente para cada uno de los conceptos principales.

Figura 1. Representación de terremoto y maremoto: definidoras y su distancia semántica (A y B; $n=240)$; y comparación según exposición (C y D; n= 104 y 136 respectivamente).

Comparación del significado de maremoto para expuestos directa y vicariamente al desastre. Los participantes expuestos de Constitución definen maremoto mayoritariamente utilizando definidoras clasificables como sentimientos y emociones negativas que se generan en el momento del desastre: miedo, desesperación, angustia, pena, susto, incertidumbre, tristeza y terror, algunas definidoras categorizables como consecuencias del desastre pérdida, muerte y destrucción- palabras asociadas a las características específicas del fenómeno -agua y ruido, otras a la familia -familia- y una última palabra definidora referida a acción de afrontamiento inmediato del desastre -arrancar-. Los participantes expuestos vicariamente (Punta Arenas) definen maremoto con palabras definidoras categorizables como sentimientos y emociones negativas que se generan en el momento del desastre: miedo, desesperación, terror, angustia, dolor, tristeza, pena y pánico, algunas definidoras referidas a consecuencias del desastre; muerte, destrucción, desastre y pérdida, y palabras relativas a agua (mar, agua y ola).

Para los participantes de Constitución las palabras observadas en el conjunto SAM relativo a la palabraestímulo maremoto son encabezadas por la definidora miedo, seguida por desesperación, observándose una distancia semántica de $48 \%$ entre ambas. Para los participantes de Punta Arenas el núcleo de red también es iniciado por la palabra definidora miedo, pero va seguido por muerte y con una distancia semántica de $15 \%$. Así, para quienes estuvieron directamente expuestos, el miedo está muy por encima de otros significados, siendo por lejos el prevaleciente $\mathrm{y}$ diferenciado respecto de otros significados. 
Terremoto y maremoto: definidoras descriptoras de estados emocionales. Los participantes en general utilizan mayor cantidad de palabras definidoras asociadas a estados emocionales para definir terremoto $(8$ de 15$)$ que maremoto $(6 \mathrm{de}$ 15), siendo 'miedo' la utilizada más frecuentemente y objeto de más importancia. Los habitantes de Constitución producen mayor cantidad de palabras definidoras asociadas a estados emocionales al significar terremoto ( 8 de 15 palabras) en tanto que al definir maremoto ( 5 de 15$)$ es el que menos definidoras de este tipo produce. Los habitantes puntanerenses para definir terremoto y maremoto utilizan la misma cantidad de palabras referidas a estados emocionales (6 de 15) mostrando así una menor diferenciación emocional entre ambas palabrasestímulo.

La diversidad de estados emocionales presentes en los núcleos de red estudiados en orden de frecuencia e importancia para los participantes fueron: miedo, desesperación, angustia, tristeza, dolor, pánico, sufrimiento, pena, temor y finalmente susto, los que en su mayoría estuvieron presentes en las personas directamente expuestas al desastre en el momento preciso de éste, y en las vicariamente expuestas en el momento de ver u oír sobre lo acontecido en la zona centro sur de Chile luego del 27/F/10.

Síntesis de resultados. Las palabras definidoras más importantes, según su jerarquía y frecuencia son miedo y muerte. Al comparar los núcleos de red para ambas palabras estímulos se encontró que 11 de las 15 palabras constitutivas de aquellas estaban presentes en ambos conjuntos SAM a la vez, es decir, el $73 \%$ de las palabras definidoras que las personas utilizan para definir la palabra estímulo terremoto son también utilizadas para definir la palabra estímulo maremoto. Estas son: miedo, muerte, destrucción, desesperación, desastre, pérdida, angustia, tristeza, pena, dolor y pánico.

Las personas de Constitución y de Pta. Arenas no muestran diferencias en las definidoras obtenidas respecto de terremoto. Estas corresponden mayoritariamente al tipo sentimiento o emoción, donde 11 de las 15 palabras definidoras están presentes en los conjuntos SAM de ambas muestras, convergiendo así en un $73 \%$ en las definidoras que utilizan para significar terremoto. Respecto de maremoto, también convergen en las palabras definidoras aunque en proporción un poco menor; 67\% (10 de las 15 palabras del núcleo de red) son las mismas en una muestra y otra. La mayoría de ellas pertenecen a la categoría semántica sentimiento o emoción, y con algunos elementos relacionados con agua. La definidora miedo encabezó la lista para ambas muestras. El tipo de definidoras más utilizadas para la muestra total, independientemente de la ciudad, son del tipo sentimientos o emociones abarcando entre un $53 \%$ y $33 \%$ del total de palabras definidoras presentes en cada núcleo de red.

\section{CONCLUSIÓN}

La representación de los conceptos terremoto y maremoto coinciden casi de manera exacta entre ambos grupos, no obstante haber tenido diferentes tipo de exposición. Probablemente ello se explica por el hecho de que en todo el país los efectos de ambos eventos fueron ampliamente difundidos por los medios de comunicación masivos (televisión, radio e internet), lo que de algún modo tiende a instalar una misma representación del desastre a nivel colectivo. Así, el o los significados de eventos de fuerte impacto psicosocial pueden llegar a ser muy similares, independientemente del tipo y grado de exposición. Las palabras definidoras empleadas por los participantes de ambas ciudades costeras para definir terremoto se relacionan tanto con sentimientos y emociones como con consecuencias del desastre. En el caso de la palabra estímulo maremoto se agrega a ello una tercera categoría que corresponde a 'salida del mar'.

Una explicación alternativa -o complementaria- a la influencia mediática homogenizadora es que las representaciones que las personas tienen de un desastre pueden ser pre-existentes al desastre mismo. Así, a una amplia y reiterada difusión mediática de mismas imágenes y relatos desastrosos se agregaría una representación cultural compartida o colectiva que la población adulta ya tiene de este tipo de fenómenos -especialmente de terremotos-, más allá de los distintos tipos y grados de exposición ambiental o de diferencias individuales. Sobre aquella cada individuo significa -eventualmente con algunos matices idiosincráticos- su realidad en relación a la experiencia que haya tenido con el hecho.

El significado obtenido respecto de terremoto y maremoto para ambas muestras está constituido por definidoras agrupables como sentimientos y emociones, y consecuencias del desastre. Además para el caso de la palabra estímulo maremoto, por palabras relativas a agua o salida del mar. Así, el contenido de la representación que las personas tienen de un hecho, más que ser de carácter individual o idiosincrático aparece como culturalmente compartido, y como socialmente construido tomando la forma de estereotipos culturales (Tajfel, 1981). Es muy probable que su generación se produzca gracias a las repeticiones reiteradas de imágenes como es habitual en la televisión comercial de hoy en que se transmiten 
y retransmiten programas construidos ad-hoc acerca de la tragedia ('informes especiales') y que se tornan temas de conversación en las familias y posteriormente en el trabajo y entre amigos $y$ conocidos.

Para explicar la similitud de significados representacionales en ambas ciudades se puede utilizar el modelo general del procesamiento de la información y de actitud, comportamientos y riesgos frente a desastre naturales y tecnológicos (Moyano Díaz \& Olivos, 1997). Si revisamos el contenido de cada uno de los componentes de ese modelo, muy probablemente sean similares para todos los habitantes de Chile. La socialización de chilenos incluye desde muy temprano la ocurrencia de temblores, terremotos (y desde ahora de maremotos) y los comportamientos apropiados de afrontamiento han sido enseñados formal e informalmente desde siempre. Sin duda alguna que gracias a esa educación (incluyendo una ingeniería que también es producto de aquella) es que el 27/F/10 (8.8 Richter más maremoto), causó solo poco más de 500 personas muertas y desaparecidas. En ese sentido, Constitución y Punta Arenas no son muy distintas; sus habitantes han estado expuestos a influencia educacional y recientemente expuestas a la información dada por los medios de comunicación respecto del desastre, lo que tal vez explique la conformación de una imagen representacional y lingüística similar en ambos grupos.

Lo anterior permite reflexionar respecto del rol de los medios de comunicación informando de desastres naturales y su efecto en los significados que las personas construyen de los mismos y sobre su bienestar y salud mental. Siendo muy deseable o positivo que un país disponga de medios libres de expresión, el conocimiento que hoy se tiene de los efectos de la comunicación sobre la salud mental de las personas hace aconsejable evitar una reiteración de imágenes dramáticas por medio de la tv hacia un público que hay que cuidar en aras de la salud como valor superior y propio de sociedades desarrolladas y no ignorantes de los efectos deletéreos o iatrogénicos de aquellas reiteraciones. Recibir o retransmitir en algún noticiero del día imágenes (dramáticas) del terremoto ocurrido en Japón el 11/03/2011 es informativo y hasta allí comprensible para el mundo interconectado actual, aunque ello ciertamente aumentó respuestas emocionales de miedo en la población chilena. Sin embargo, repetir una y otra vez lo mismo en diferentes horarios y bajo distintos pretextos es impropio y no saludable para una población ya expuesta. El reciente terremotomaremoto de Japón (a poco más de un año del 27/F/10), trajo como consecuencia acciones de evacuación preventiva de algunos sectores costeros de
Chile, lo que sin duda evocó significados y reacciones emocionales negativas para la salud mental. Esto, junto con los efectos comunicacionales referidos, podría por cierto constituir interesante tema de investigación.

La palabra miedo es la más importante en los participantes de ambas muestras; la naturaleza impredecible e incontrolable del evento activaría en las personas respuestas emocionales de miedo e inseguridad frente a eventos que históricamente han sido muy destructivos (Novoa, 2006). Las personas de Constitución que estaban en las viviendas de emergencia ubicadas en el mismo lugar en donde se hallaban sus antiguas casas arrasadas por el maremoto fueron quienes mostraron mayor tensión psicológica en las entrevistas, en línea de lo formulado por Joh (1997). Otro elemento recogido en terreno fue la expresión de religiosidad en muchos entrevistados quienes hicieron referencia a su creencia en Dios, y a la importancia de ello a la hora de enfrentar de manera positiva el desastre, además de señalarlo como una prueba divina que debían superar, y a su vez dar gracias por la oportunidad que significaba estar vivos. Resulta importante incluir el componente religioso en futuras investigaciones ya que podría explicar eventuales representaciones y formas características de afrontar las consecuencias psicológicas, sociales y económicas del desastre. Al respecto Aspinwall (2001) señala que junto al humor y a las interacciones sociales, el uso de la religión en situaciones adversas se puede interpretar como un mecanismo de regulación del impacto del desastre.

La gran similitud entre las R.S. de las personas expuestas y no expuestas directamente a un terremoto y maremoto, también incluye algunas diferencias que, aunque sutiles, pueden ser potencialmente relevantes para la investigación. La primera es que las directamente expuestas al desastre tienden a utilizar más palabras definidoras subjetivas y emocionales (80\%) que las vicariamente expuestas (53\%) y éstas, más palabras categorizables como 'objetivas y racionales' para ambas palabras estímulo.

\section{REFERÊNCIAS}

Aspinwall, L. (2001). Dealing with adversity: selfregulation, coping, adaptation and health. In A. Tesser \& N. Schwarz (Eds.). The Blackwell handbook of social psychology: vol 1. Intraicolendividual processes (pp. 559-614). Malden, Massachusetts: Blackwell Publishing.

Bandura, A. (1970). Modeling theory: Some traditions, trends, and disputes. In W. S. Sahakian (Ed.), Psychology of learning: Systems, models, and theories. Chicago: Markham. 
Bandura, A. (1986). Social Foundations of Thought and Action: A Social Cognitive Theory. Englewood Cliffs, NJ.: Prentice-Hall.

Cárdenas, M. (2008). El análisis multivariante de las representaciones sociales. Antofagasta: Editorial Universidad Católica de Norte.

Enrique, J. (2002) Políticas públicas para la reducción de la vulnerabilidad frente a los desastres naturales $y$ socio-naturales. CEPAL-SERIES, Medio ambiente y desarrollo. Santiago: Naciones Unidas.

Farr, R. (1986). Las representaciones sociales. In S. Moscovici. Psicología Social II. (pp. 495-506). Barcelona: Paidós.

García, F., \& Mardones, R. (2010). Prevención de trastorno de estrés postraumático en supervivientes. Terapia Psicológica, 28 (1), 85-93.

Gascón, M. (2009) Percepción del desastre natural. Buenos Aires: Biblos-Intertextos.

Ilustre Colegio Oficial de Geólogos (2011). El seísmo de Japón liberó energía como 10.000 bombas de Hiroshima. Recuperado em 5 de enero, 2012, de http://www.icog.es/_portal/noticias/noticias.asp?bid=1 854\&ini $=1$

Jiménez, A., \& Cubillos, R. (2010). Estrés Percibido y Satisfacción Laboral después del Terremoto. Terapia Psicológica, 28 (2), 187-192.

Jodelet, D. (1984). La representación social: fenómeno, concepto y teoría. In S. Moscovici. Psicología Social II. (pp. 470-494). Barcelona: Paidós.

Joh, H. (1997). Disaster stress of the 1995 Kobe earthquake. Psychologia: An International Journal of Psychology in the Orient, 40, 192-200.

Ligi, G. (2005) La inundación del Vojont, representaciones periodísticas de un desastre italiano. Desacatos, Revista de Antropología Social. 19, 71-84.

Lorito, S., Romano,F., Atzori, S., Tong, X., Avallone, A., McCloskey, J., et al. (2011). Limited overlap between the seismic gap and coseismic slip of the great 2010 Chile earthquake. Nature Geoscience 4, 173-177.

Moyano Díaz, E., \& Olivos, P. (1997). Psicología y desastres ambientales en Chile. Revista Desastres y Sociedad, 8 (5), 112-119.

Moyano-Díaz, E., Maturana, B., \& Villablanca, L. (2002). Actitud proambiental y reactividad de comunidades hacia la construcción de vertederos de basura en sus entornos. En Guevara, J., \& Mercado, S. (Coords) Temas selectos de Psicología Ambiental (pp. 411-441). México: UNAM.

Novoa, M. (2006). Percepción humana de las catástrofes. Revista I.T., 74, 4-13.

ONEMI - Oficina Nacional de Emergencia (2010). Sismos del siglo XX y XXI, 2010. Santiago: Gobierno de Chile. Ministerio del Interior. Recuperado em 5 de enero, 2012, http://www.onemi.cl/archivos/1/22/file_20100518_509 4.pdf

PAHO - Panamerican Health Organization (2010). El terremoto y el tsunami del 27 de febrero en Chile: Crónicas y lecciones aprendidas en el sector salud [The earthquake and tsunami in Chile February 27: Chronicles and lessons learned in the health sector]. Santiago de Chile: PAHO.

Riquelme, P. (2010/02/28). Tres enormes olas devastan Constitución tras sismo. La Tercera, 8-9.

Tajfel, H. (1981). Human Groups and Social Categories. Cambridge: Cambridge University Press.

Trejo, H., Camacho, R., Herrera, J., \& González, A. (2011). Significado semántico de «lactancia materna» y «lactancia artificial», en mujeres y hombre. Revista Mexicana de Pediatría, 78(1), 10-15.

USGS - United States Geological Survey (2010). Informe Preliminar del Sismo. Recuperado em 5 de enero, 2012, http://neic.usgs.gov/neis/bulletin/neic_tfan_esp.html

Valdez, M. (1998). Redes semánticas naturales, usos, aplicaciones en Psicología Social. Toluca. México: Universidad Autónoma del Estado de México.

Zermeño, A., Arellano, A., \& Ramírez, V. (2005). Redes Semánticas Naturales: Técnica para representar los significados que los jóvenes tienen sobre televisión, internet y expectativas de vida. Revista Estudios sobre las culturas contemporáneas, 11(22) 305-334.

Recebido em 27-07-2012 Aceito em 25-09-2012
Endereço para correspondência:
Emilio Moyano Díaz. Facultad de Psicología, Universidad de Talca. Avenida Lircay s/n. Talca, Chile.E-mail: emoyano@utalca.cl. 